\title{
Sistem Informasi Eksekutif Aplikasi Rumah Sakit Berbasis Web \& Mobile System ( Studi Kasus : Rs. Tugurejo Semarang )
}

\author{
Penny Hendriyati1, Roy Amrullah Ritonga2, Anita Megayanti3 \\ 1,3 STTIKOM Insan Unggul Cilegon, JL Sultan Ageng Tirtayasa Kav. 25-28 No. 14642414 \\ ${ }^{2}$ Sekolah Tinggi Ilmu Komputer Al-Khairiyah Cilegon, Jalan H. Enggus Arja No. 1, \\ Citangkil, Kec. Cilegon, Kota Cilegon, Banten 42441 \\ Email: roy.amrullah@gmail.com ${ }^{2}$, Penny.hendriyati@gmail.com ${ }^{1}$ anita.megayanti@gmail.com ${ }^{3}$
}

Article history

Received Jul 28, 2020

Revised Okt 13, 2020

Accepted Nov 02, 2020

Available Online Nov 28, 2020

Keywords

Executive Information Systems,

Mobile Application systems, fishbone diagrams,

Management Information Systems, Decision Support Systems.

Riwayat

Diterima 28 Jul 2020

Revisi 13 Okt 2020

Disetujui 02 Nov 2020

Terbit 28 Nov 2020

Kata Kunci

Sistem Informasi Eksekutif,

Aplikasi Mobile sistem,

fishbone diagram, Management Information System, Decision

Support Sistem.

\section{Abstract}

Hospital Application Executive Information System is a system that provides information for executives about the overall performance of a company or agency. Hospital has the function and objective of health service facilities which provide service activities in the form of outpatient services, inpatient services, emergency services, referral services which include medical record services and medical support and are used for education, training and research for health workers. With the existence of this executive information system, it becomes a combination of the Management Information System (MIS) with the Decision Support System (DSS) and AIat to help executives identify the basis of a problem and find a solution. So it is not impossible that the executives of Tugurejo Hospital need information that is useful, accurate and fast. However, based on the survey and interviews the author conducted, it was found that executives at these hospitals took a long time to get accurate information. This was partly due to the difficulties in functioning at the time of data collection, because the source data were not well organized and were still separated from one another, manual recording was still done and the lack of executive support facilities required for information. The right solution to solve this problem is to create an Executive Information System application based on web \& mobile systems. With the development of a web \& mobile-based Executive Information System this system is intended to help provide the information needed by Rs executives. Tugurejo to analyze or monitor the development of tugurejo hospital services in Semarang City that are faster and more focused through reports in the form of graphs or tables that can drilldown to a more specific level, so that the information received can be more easily understood and can see detailed information and can be accessed anywhere without time and space limits. While the method used to analyze the problem is the Fishbone Diagram.

\section{Abstrak}

Sistem Informasi Eksekutif Aplikasi Rumah Sakit merupakan suatu sistem yang menyediakan informasi bagi eksekutif mengenai kinerja keseluruhan perusahaan ataupun instansi. Rumah Sakit mempunyai fungsi dan tujuan sarana pelayanan kesehatan yang menyelenggarakan kegiatan pelayanan berupa pelayanan rawat jalan, pelayanan rawat inap, pelayanan gawat darurat, pelayanan rujukan yang mencakup pelayanan rekam medis dan penunjang medis serta dimanfaatkan untuk pendidikan, pelatihan, dan penelitian bagi para tenaga kesehatan. Dengan adanya Sistem informasi eksekutif ini menjadi kombinasi antara Management Information Sistem (MIS) dengan Decision Support Sistem (DSS) dan AIat untuk membantu pihak eksekutif dalam mengidentifikasikan dasar suatu masalah dan mencari jalan keluarnya. Sehingga bukan tidak mungkin para eksekutif Rumah Sakit Tugurejo membutuhkan informasi yang berguna, akurat dan cepat. Namun, berdasarkan survei dan wawancara yang penulis lakukan, bahwa para eksekutif di rumah sakit tersebut membutuhkan waktu lama untuk mendapatkan informasi yang akurat. Hal ini sebagian disebabkan oleh 
kesulitan yang berfungsi pada saat pengumpulan data, karena data sumber belum terorganisasi dengan baik dan masih terpisahkan antara satu sama lain, pencatatan masih dilakukan secara manual serta kurangnya fasilitas pendukung eksekutif yang diperlukan untuk informasi. Solusi yang tepat untuk memecahkan masalah ini adalah dengan membuat aplikasi Sistem Informasi Eksekutif berbasis web \& mobile sistem. Dengan dibangunnya Sistem Informasi Eksekutif berbasis web \& mobile sistem ini dimaksudkan untuk membantu memberikan informasi yang dibutuhkan oleh eksekutif Rs. Tugurejo untuk menganalisa atau memantau pengembangan pelayanan rumah sakit tugurejo di Kota Semarang yang lebih cepat dan lebih fokus melalui laporan berupa grafik atau tabel yang bisa drilldown ke tingkat yang lebih spesifik, sehingga informasi yang diterima bisa lebih mudah dipahami dan bisa melihat informasi terperinci serta bisa diakses dimanapun tanpa ada batas waktu dan ruang. Sedangkan metode yang digunakan untuk menganalisa masalah adalah Fishbone Diagram. 


\section{PENDAHULUAN}

RSUD Tugurejo terletak di Jalan Raya Tugurejo Kecamatan Tugu, Semarang. Pelayanan yang diberikan antara lain poliklinik penyakit dalam, poliklinik bedah, poliklinik anak, poliklinik syaraf, poliklinik mata, poliklinik kulit, poliklinik gigi, anastesi, radiologi, patologi klinik, patologi anatomi, psikologi, poliklinik obsgyn, orthopedi serta trauma center. Dengan banyak pelayanan langsung dengan pasien (end customer) maka dipandang perlu untuk melakukan pembenahan dan perhatian khusus yang lebih besar dalam perbaikan pelayanan. Oleh karena tugas dari front office di Rumah Sakit sangat rentan hubungannya dengan public, tidak jarang pihak eksekutif RSUD Tugurejo membutuhkan informasi yang berguna, tepat dan cepat. Berdasarkan survei dan wawancara yang telah penulis laksanakan, informasi yang dibutuhkan oleh seorang eksekutif tidak hanya berasal dari satu sumber data saja, melainkan data-data tersebut berasal dari sub-sub divisi pada RSUD Tugurejo. Maka untuk melakukan evaluasi data diperlukan waktu yang cukup lama. Hal ini antara lain disebabkan karena pencatatan masih dilakukan secara manual, kurangnya fasilitas sharing data antar sub bagian, dan sumber data yang masih belum terodinir dengan baik. Di sisi lain, seorang eksekutif RSUD tugureko juga memerlukan informasi yang mudah dibaca mudah dimengerti mudah diakses dimanapun serta dapat memperoleh detail dari informasi tersebut. Jadi untuk mengatasi permasalahan tersebut diperlukan suatu Sistem Informasi Eksekutif yang berbasis web dan mobile system yang lengkap, terpadu, praktis dan mudah serta siap digunakan setiap saat bagi pihak eksekutif RSUD Tugurejo sehingga dapat mendukung proses pengambilan keputusan secara cepat, tepat dan terarah. Sedangkan maksud dari berbasis web yaitu untuk memberikan fasilitas sharing data antar sub bagian. Dalam hal untuk menunjang kebutuhan eksekutif akan informasi, suatu Sistem Informasi Eksekutif juga menawarkan informasi yang dapat berupa laporan dalam berbentuk grafik atau tabel yang mudah dipahami dan dimengerti serta laporan tersebut dapat di drilldown menjadi laporan yang lebih spesifik dan mendetail lagi.

Penulis juga menyebarkan kuisoner kepada pada manajemen RSUD tugurejo untuk memperoleh masalah-masalah yang menyebabkan sistem informasi eksekutif belum bisa diakses sepenuhnya oleh para eksekutif rumah sakit. Dengan menyebarkan angket ini maka diperolehlah solusi bahwa sistem informasi eksekutif RSUD tugurejo berbasis web dan mobile system dikarenakan pada era tehnologi sudah banyak para eksekutif menggunakan smartphone.

Sistem Informasi Eksekutif merupakan suatu sistem yang khusus dirancang bagi manajer tingkat perencanaan strategis yang menyediakan informasi bagi eksekutif mengenai kinerja keseluruhan perusahaan. Informasi dapat diambil dengan mudah dan dalam berbagai tingkat rincian. Informasi dapat ditampilkan dengan bentuk grafik, tabel, atau narasi.

Berbeda dengan tipe sistem informasi yang lain, pada dasarnya EIS tidak dirancang untuk menyelesaikan masalah tertentu. EIS dirancang untuk membantu eksekutif mencari informasi yang diperlukan manakala mereka membutuhkannya dan dalam bentuk apa pun yang paling bermanfaat. Sebagai implementasinya, pemakai EIS dapat memilih format grafik, mengatur tampilan informasi yang dikehendaki, dan mengetahui pemicu laporan perkecualian. Kemampuan drilldown yang tersedia pada sistem ini memungkinkan eksekutif dapat melihat rinci suatu informasi. (Kadir, 2003:122).

Aplikasi Web Menurut Janner Simarmata, aplikasi web adalah sebuah sistem informasi yang mendukung interaksi pengguna melalui antarmuka berbasis web. Aplikasi web merupakan bagian dari client-side yang dapat dijalankan oleh browser web.

Interaksi web dibagi menjadi sebagai berikut :

1. Permintaan

2. Pemrosesan

3. Jawaban

Aplikasi web merupakan sebuah aplikasi yang mengunakan teknologi browser untuk menjalankan aplikasi dan diakses melalui jaringan 
komputer (Remick, 2011). Sedangkan menurut (Rouse, 2011) aplikasi web adalah sebuah program yang disimpan di Server dan dikirim melalui internet dan diakses melalui antarmuka browser.

Dari pengertian diatas dapat disimpulkan aplikasi web merupakan aplikasi yang diakses mengunakan web berowser melalui jaringan internet atau intranet. Aplikasi web juga merupakan suatu perangkat lunak komputer yang dikodekan dalam bahasa pemrograman yang mendukung perangkat lunak berbasis web seperti HTML, JavaScript, CSS, Ruby, Python, Php, Java dan bahasa pemrograman lainnya.

Menurut Wikipedia, pengertian aplikasi adalah program yang digunakan orang untuk melakukan sesuatu pada sistem komputer. Mobile dapat diartikan sebagai perpindahan yang mudah dari satu tempat ke tempat yang lain, misalnya telepon mobile berarti bahwa terminal telepon yang dapat berpindah dengan mudah dari satu tempat ke tempat lain tanpa terjadi pemutusan atau terputusnya komunikasi. Sistem aplikasi mobile merupakan aplikasi yang dapat digunakan walaupun pengguna berpindah dengan mudah dari satu tempat ketempat lain lain tanpa terjadipemutusan atau terputusnya komunikasi. Aplikasi ini dapat diakses melalui perangkat nirkabel seperti pager, seperti telepon seluler dan PDA. Mobile bersifat bebas seperti air dan dapat mengalir kemanapun sehingga mobile dapat berubah dan diubah dengan mudah.

Adapun tujuan dan manfaat dari penelitian ini adalah sebagai berikut :

1. Untuk mengetahui perananan teknologi informasi pada Rumah Sakit Tugurejo Kota Semarang

2. Untuk mengetahui secara real penerapan aplikasi terhadap teknologi informasi pada Rumah Sakit Tugurejo Kota Semarang.

3. Untuk memahami pendekatan informasi pada Rumah Sakit Tugurejo Kota Semarang dengan menggunakan metode Fishbone.

4. Untuk memahami peranan teknologi informasi dalam manajemen strategik sebagai pengambil keputusan.

\section{KAJIAN LITERATUR DAN PEGEMBANGAN HIPOTESIS.}

- Pada Penelitian sebelumnya mengenai Sistem Informasi Eksekutif Berbasis Web Pada Stasiun Pengisian Bahan Bakar Umum (Spbu) PT. Pertamina, bahwa informasi yang dibutuhkan oleh seorang eksekutif berasal dari sub-sub divisi pada fungsi Fuel Retail Marketing Regional V yang membutuhkan evaluasi data diperlukan waktu yang cukup lama dikarenakan pencatatan masih dilakukan secara manual, kurangnya fasilitas sharing data antar sub bagian, dan sumber data yang masih belum terodinir dengan baik maka diperlukannya sistem informasi eksekutif berbais Web agar informasi yang mudah dibaca dan laporan yang diperoleh dapat di drilldown menjadi laporan yang lebih spesifik dan mendetail lagi.[Ode Ostarita, dkk]

- Sistem Informasi Eksklusif Berbasis Web dikembangkan agar dapat menangani permintaan informasi dari untuk kalangan eksekutif yang menjadi pimpinan berfungsi sebagai fasilitator dalam melakukan evaluasi civitas akademik dengan informasi yang tepat, akurat dan cepat sesuai dengan salah satu tujuan dari pengembangan sistem Informasi Eksklusif Berbasis Web Pada Fakultas Teknik Universitas Dipeneogoro yaitu Sistem dapat menyimpan semua data yang berhubungan dengan permintaan kebutuhan eksekutif dengan untuk memudahkan dalam dokumentasi data.[Anil Dawan]

- Seperti halnya pada Swalayan Koperasi Petra Pertamina Plaju Unit II, dalam penyampaian laporan masih dilakukan dengan cara yang konvensional sehingga tidaklah efesien sehingga mengakibarkan proses sintesa terhadap suatu permasalahan yang seharusnya cepat mengambil keputusan dari permasalahan tersebut maka 
sangat diperlukannya suatu perangkat lunak sistem informasi eksekutif untuk membantu para pimpinan dalam mengatasi masalah penyajian informasi terhadap laporan yang akan diberikan kepada para manajerial atas.[Jurnal Apriansyah Putra]

\section{METODE PENELITIAN}

Metode pengumpulan data dilakukan dengan 2 (dua) cara yakni :

\section{a. Observasi}

Observasi dilakukan untuk mendapatkan informasi mengenai masalah-masalah yang terjadi mengenai system informasi eksekutif di RSUD tugurejo. Peneliti memberikan kuisioner kepada pihak manajemen RSUD Tugurejo seberapa besar informasi yang didapat dari hasil laporan-laporan yang mempengaruhi dalam proses pengambilan keputusan,

b. Wawancara

Wawancara dilakukan untuk mengidentifikasi kebutuhan system informasi eksekutif agar lebih cepat dan akurat yang dapat membantu dalam pengambil keputusan para eksektutif RSUD tugurejo.

Pada umumnya mengidentifikasi atau menganalisa masalah dapat menggunakan beberapa metode, salah satunya dengan menggunakan diagram tulang ikan atau fishbone diagram. Fishbone Diagram atau Ishikawa merupakan sebuah alat grafis yang digunakan untuk mengidentifikasi,mengeksplorasi dan menggambarkan suatu masalah,sebab dan akibat dari masalah itu (Jubaedi dkk,2013). Dari hasil penelitian yang dilakukan, masalah yang dihadapi dalam perusahaan ini digambarkan dalam diagram tulang ikan (Fishbone Diagram) sebagai berikut :

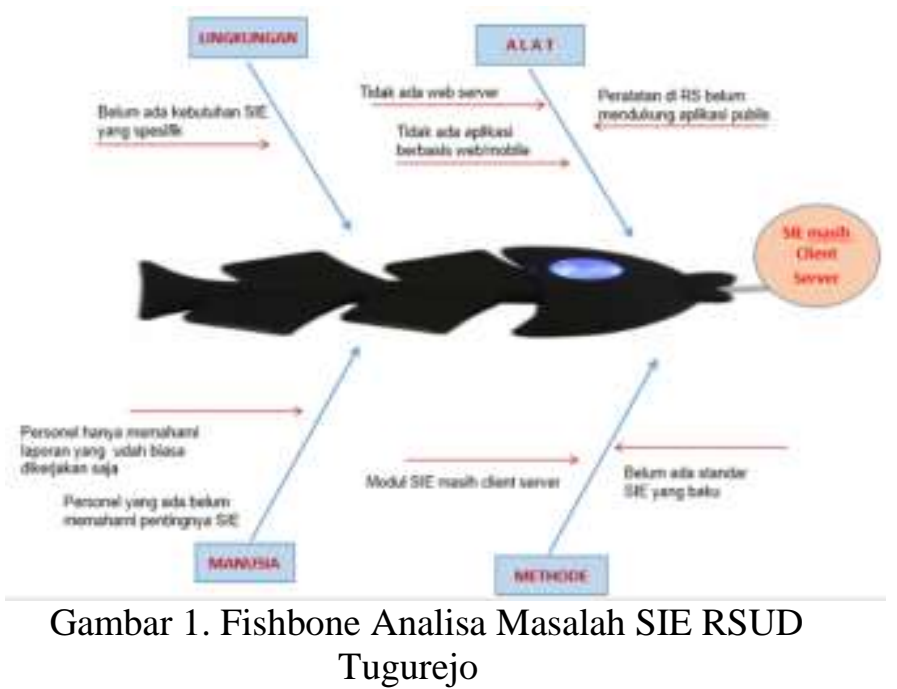

Gambar diatas menjelaskan bahwa masalah utamanya terletak pada system informasi eksekutif masih menggunakan client server. Sedangkan faktorfaktor yang menyebabkan masalah utama tersebut berasal dari beberapa aspek, diantaranya : lingkungan, alat, manusia dan method. Dari kempat faktor tersebut setelah dilakukan analisa lebih detail maka adanya masalah-masalah dominan yang dihadapi oleh RSUD tugurejo dalam system informasi eksekutif yaitu :

1. Aplikasi masih cliet server (belum berbasis web/mobile)

2. Belum adanya web server dan IP publick

3. Belum memahami akan kebutuhan SIE yang spesifik

4. Personel masih terpaku pada laporan konvensional

\section{HASIL DAN PEMBAHASAN}

Dari hasil beberapa masalah dominan diatas maka peneliti mengunakan metode $5 \mathrm{~W} 1 \mathrm{H}$ dalam mengusulkan solusi-solusi untuk mengatasi masalah tersebut. 
Tabel 1 . Alternatif Solusi

\begin{tabular}{|c|c|c|c|c|c|c|}
\hline $\begin{array}{c}\text { Faktor Penyebab } \\
\text { Dominan }\end{array}$ & What & Why & Where & When & Who & How \\
\hline $\begin{array}{l}\text { Aplikasi masih cliet } \\
\text { server (belum } \\
\text { berbasis } \\
\text { web/mobile) }\end{array}$ & $\begin{array}{l}\text { Aplikasi SIE } \\
\text { (Sistem } \\
\text { Informasi } \\
\text { Eksekutif) }\end{array}$ & $\begin{array}{l}\text { Agar dibuatkan } \\
\text { aplikasi SIE berbasis } \\
\text { web/mobile }\end{array}$ & $\begin{array}{l}\text { RSUD } \\
\text { Tugurejo }\end{array}$ & Okt-19 & $\begin{array}{l}\text { Penny, } \\
\text { Anita, } \\
\text { Roy }\end{array}$ & $\begin{array}{l}\text { Aplikasi dibuat } \\
\text { menggunakan } \\
\text { PHP web dan } \\
\text { PHP mobile }\end{array}$ \\
\hline $\begin{array}{l}\text { Belum adanya web } \\
\text { server dan IP public }\end{array}$ & $\begin{array}{l}\text { Server web dan } \\
\text { IP public }\end{array}$ & $\begin{array}{l}\quad \text { - Agar aplikasi } \\
\text { web/mobile tidak } \\
\text { langsung mengakses } \\
\text { data server production. } \\
\\
\quad \text { - IP publict untuk } \\
\text { mengakses aplikasi } \\
\text { bisa dari luar RS } \\
\text { menggunakan internet. }\end{array}$ & $\begin{array}{l}\text { RSUD } \\
\text { Tugurejo }\end{array}$ & Nop-19 & $\begin{array}{l}\text { Andi } \\
\text { Cahyo \& } \\
\text { Tim IT } \\
\text { RS } \\
\text { Tugurejo }\end{array}$ & $\begin{array}{l}\text { - Pengadaan } \\
\text { server } \\
\text { - Pengadaan IP } \\
\text { publik ke } \\
\text { penyedia jasa ISP }\end{array}$ \\
\hline $\begin{array}{l}\text { Personel belum } \\
\text { memahasi SIE \& } \\
\text { masih terpaku pada } \\
\text { laporan } \\
\text { konvensional }\end{array}$ & $\begin{array}{l}\text { Laporan masih } \\
\text { bersifat } \\
\text { hardcopy dan } \\
\text { softcopy kirim } \\
\text { lewat email }\end{array}$ & $\begin{array}{l}\text { - Sosialisasi fungsi } \\
\text { dan pentingnya SIE } \\
\text { - Pelatihan } \\
\text { penggunaan aplikasi } \\
\text { SIE }\end{array}$ & $\begin{array}{l}\text { RSUD } \\
\text { Tugurejo }\end{array}$ & $\begin{array}{l}\text { Nopember } \\
2019\end{array}$ & 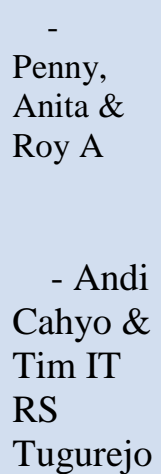 & $\begin{array}{l}\text { Pelatihan } \\
\text { personel }\end{array}$ \\
\hline
\end{tabular}

Faktor Penyebab Dominan :

a. Aplikasi masih cliet server (belum berbasis web/mobile)

\begin{tabular}{|c|l}
\hline What & $\begin{array}{l}\text { Aplikasi SIE (Sistem Informasi } \\
\text { Eksekutif) }\end{array}$ \\
\hline Why & $\begin{array}{l}\text { Agar dibuatkan aplikasi SIE berbasis } \\
\text { web/mobile }\end{array}$ \\
\hline Where & RSUD Tugurejo \\
\hline When & Okt-19 \\
\hline Who & Penny, Anita \& Roy \\
\hline How & $\begin{array}{l}\text { Aplikasi dibuat menggunakan PHP } \\
\text { web dan PHP mobile }\end{array}$ \\
\hline
\end{tabular}

b. Belum adanya web server dan IP public

\begin{tabular}{|l|l|} 
What & $\begin{array}{l}\text { Laporan masih bersifat hardcopy dan } \\
\text { softcopy kirim lewat email }\end{array}$ \\
\hline Why & $\begin{array}{l}\text { - Sosialisasi fungsi dan pentingnya } \\
\text { SIE } \\
- \text { Pelatihan penggunaan aplikasi } \\
\text { SIE }\end{array}$ \\
\hline Where & RSUD Tugurejo \\
\hline When & Nopember 2019 \\
\hline
\end{tabular}




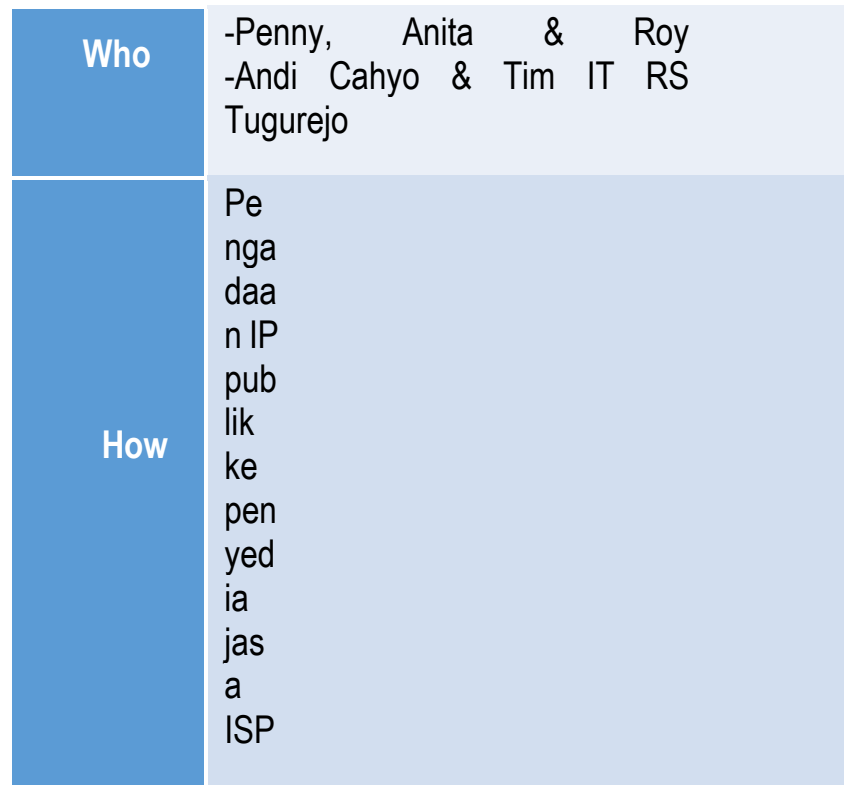

c. Personel belum memahasi SIE \& masih terpaku pada laporan konvensional
What

\begin{tabular}{|l|l|} 
Why & $\begin{array}{l}\text { - Agar aplikasi web/mobile } \\
\text { tidak langsung mengakses } \\
\text { data server production. } \\
\text { - IP publict untuk mengakses } \\
\text { aplikasi bisa dari luar RS } \\
\text { menggunakan internet. }\end{array}$ \\
\hline Where & RSUD Tugurejo \\
\hline When & $\begin{array}{l}\text { Nopember } 2019 \\
\text { Who }\end{array}$ \\
$\begin{array}{l}\text { Andi Cahyo \& Tim IT RS } \\
\text { Tugurejo }\end{array}$ \\
\hline How & $\begin{array}{l}\text { Pengadaan IP publik ke } \\
\text { penyedia jasa ISP }\end{array}$ \\
\hline
\end{tabular}

Setelah terdapat alternative solusi dan diimplementasikan di RSUD Tugurejo maka terdapat beberapa hasil dari penerapan solusi dilihat dari kualitas, biaya, pengiriman dan moralnya.

Tabel 2 . Hasil Penerapan Solusi

\begin{tabular}{|c|c|c|}
\hline KETERANGAN & SEBELUM & SESUDAH \\
\hline Kualitas & $\begin{array}{l}\text { Proses laporan SIE harus di PC } \\
\text { jaringan RS dan dikirim } \\
\text { menggunakan email }\end{array}$ & $\begin{array}{l}\text { Laporan SIE bisa langsung diakses dari luar RS } \\
\text { dan menggunakan PC Tablet, Smartphone maupun } \\
\text { PC internet. }\end{array}$ \\
\hline Biaya & $\begin{array}{l}\text { Untuk di luar RS permintaan } \\
\text { laporan SIE harus telepon ke } \\
\text { RS untuk disiapkan dan } \\
\text { dikirim ke email. } \\
\text { Untuk di lingkungan RS harus } \\
\text { menggunakan PC yang } \\
\text { terhubung dengan jaringan } \\
\text { LAN RS. }\end{array}$ & $\begin{array}{l}\text { Langsung bisa diakses melalui smartphone, pc } \\
\text { tablet atau jaringan Internet }\end{array}$ \\
\hline Pengiriman & $\begin{array}{l}\text { Waktu yang dibutuhkan } \\
\text { hingga laporan SIE diterima : } \\
\text { § Diluar RS } 15 \text { s/d } 30 \text { menit } \\
\text { § Di RS } 1 \text { s/d } 3 \text { menit }\end{array}$ & $\begin{array}{l}\text { Laporan SIE hingga data dibaca } 3 \mathrm{~s} / \mathrm{d} 5 \text { detik (real } \\
\text { time) }\end{array}$ \\
\hline
\end{tabular}




\section{Moral bertanggung jawab atas pekerjaannya karena tidak termonitor secara langsung.}

Personel (pegawai) kurang
Personel (pegawai) lebih termotifasi karena hasil kerja bisa langsung dilihat oleh pimpinan bahkan sampai ke gubernur.
Tahapan ini bertujuan untuk mengetahui kebutuhan pengguna terhadap sistem yang akan dikembangkan.Hal ini perlu dilakukan supaya apa yang dikembangkan sesuai dengan kebutuhan pengguna. Beberapa kebutuhan secara fungsional dalam menerapkan sistem informasi eksekutif RSUD tugurejo dilihat dari sisi eksternal maupun internal diantaranya sebagai berikut :

1. Eksternal
a. Meningkatan kompetisi
b. Lingkungan yang dengan cepat berubah
c. Keharusan untuk selalu proaktif
d. Kebutuhan untuk mengakses external database

2. Internal

a. Kebutuhan akan informasi yang up to date

b. Kebutuhan akan komunikasi

c. Kebutuhan akan informasi yang lebih akurat

d. Kebutuhan untuk meningkatkan keefektifan

Selain kebutuhan fungsional dalam sistem informasi eksekutif juga terdapat komponenkomponen pendukung SIE RSUD tugurejo diantaranya :

1. Hardware

Komputer : PC/ Laptop

Mobile Device : Smart Phone

2. Software

Operating Sistem : Windows, Linux, Android, IOS
Software Application : Web Browser ( Firefox, Google Chrome etc)

3. User Interface

4. Telekomunikasi

Jaringan Komputer

Intrenet Access

Pada bagian ini akan dijelaskan tampilantampilan yang ada pada Sistem Informasi Eksekutif RSUD tugurejo,sebagai berikut :

a. Halaman untuk login

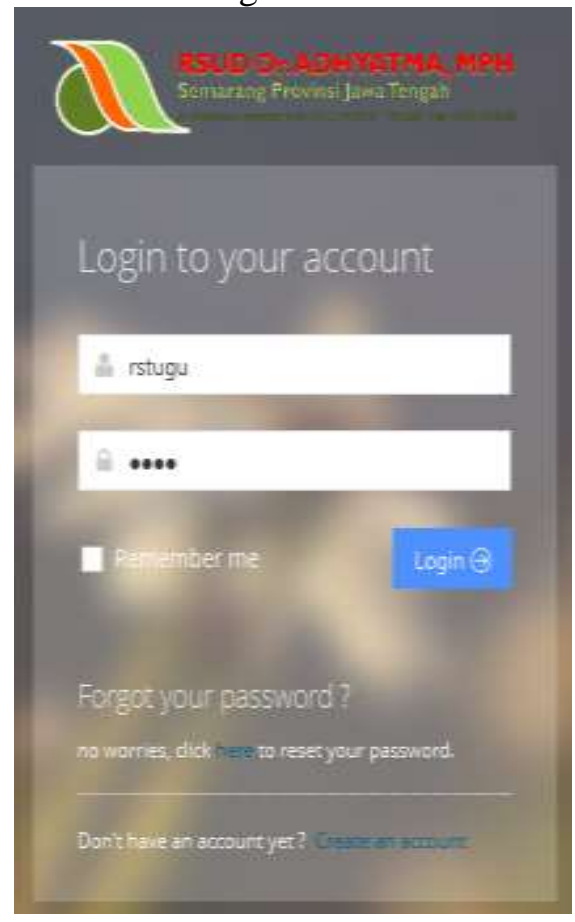

b. Dashboard sistem yang berfungsi sebagai menampilkan data statistik (grafik) tentang pelayan Pasien di rumah sakit. 


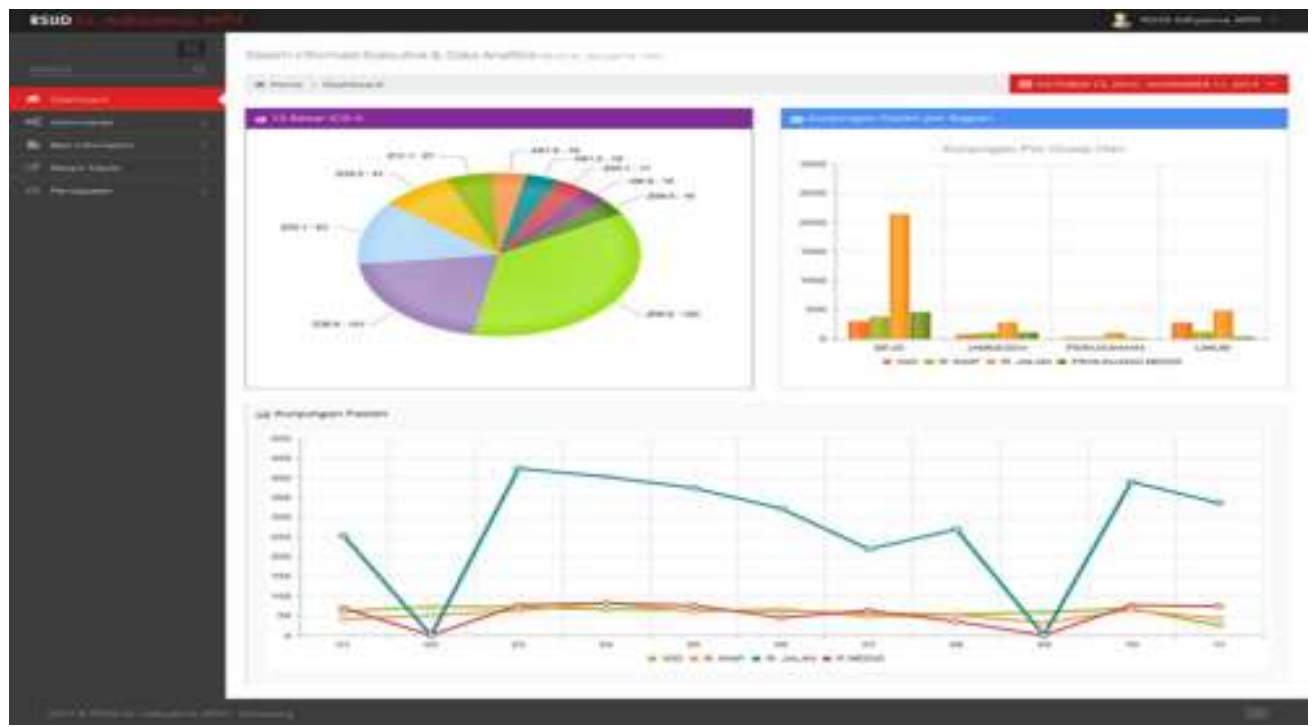

Gambar 3. Dashboard

c. Bed Information system

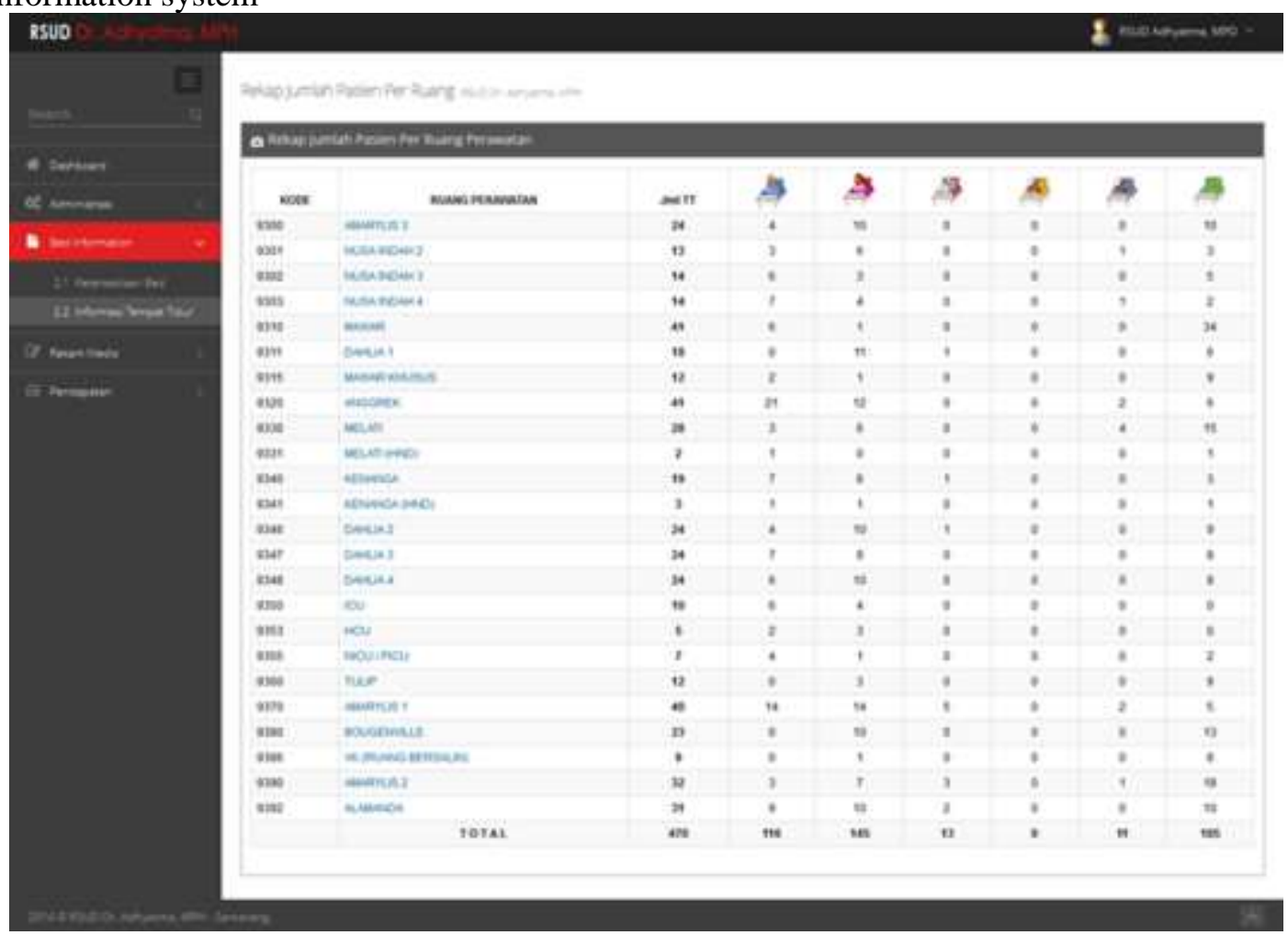

Gambar 4. Bed Information System

d. Peta tempat tidur dan kondisinya 


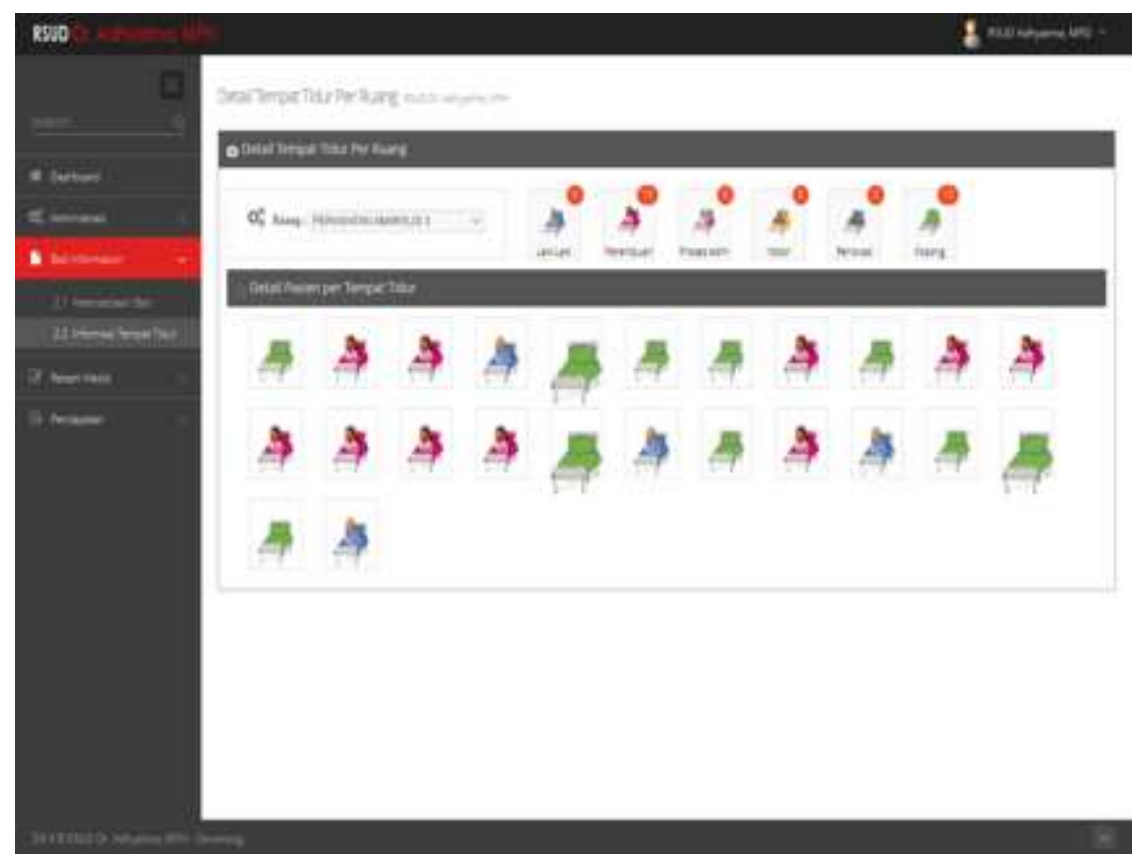

Gambar 5. Peta Tempat Tidur Dan Kondisinya

e. Daftar 10 besar penyakit berdasarkan ICD-X

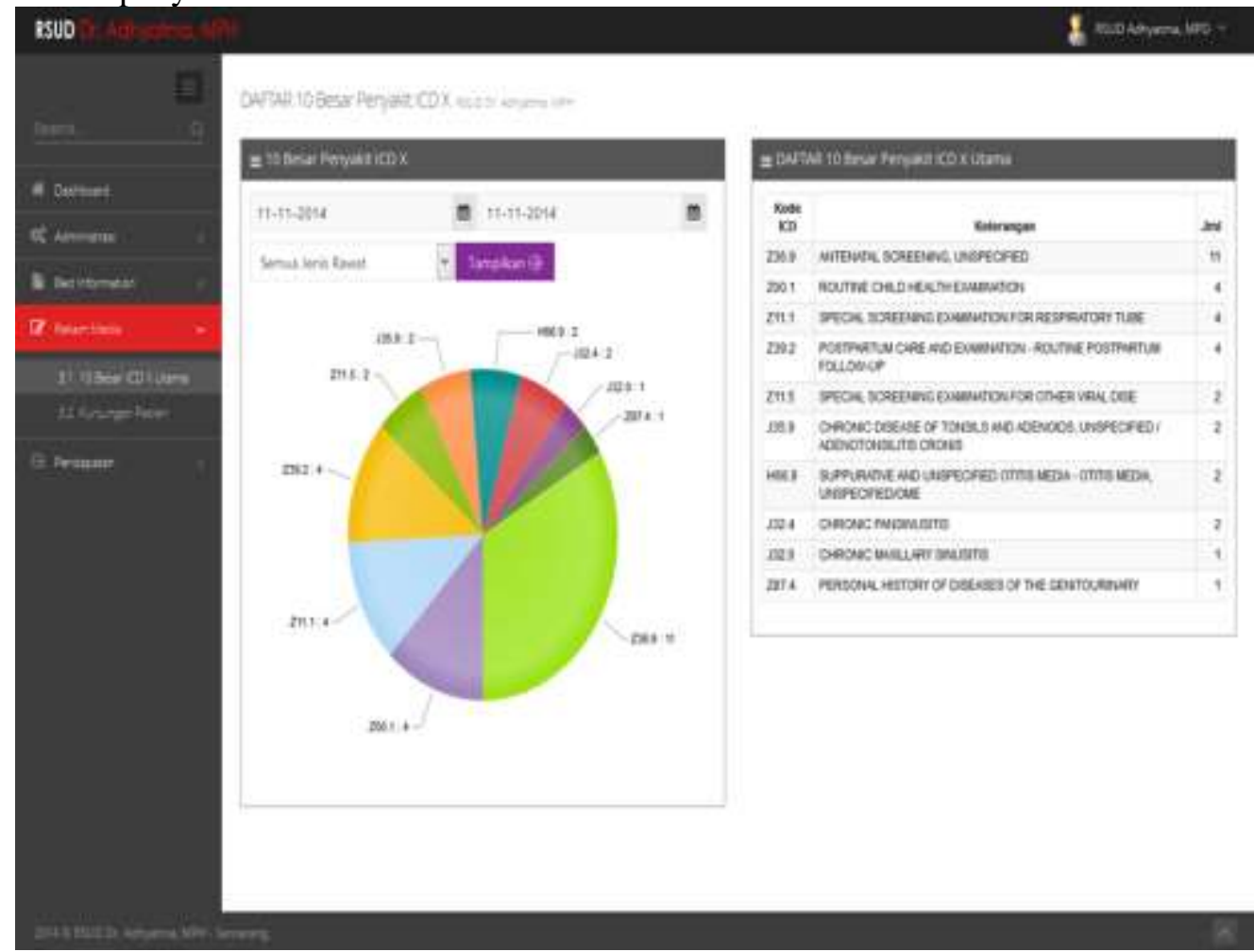

Gambar 6. Daftar 10 besar oenyakit berdasarkan ICD-X

f. Kunjungan pasien per penjamin 


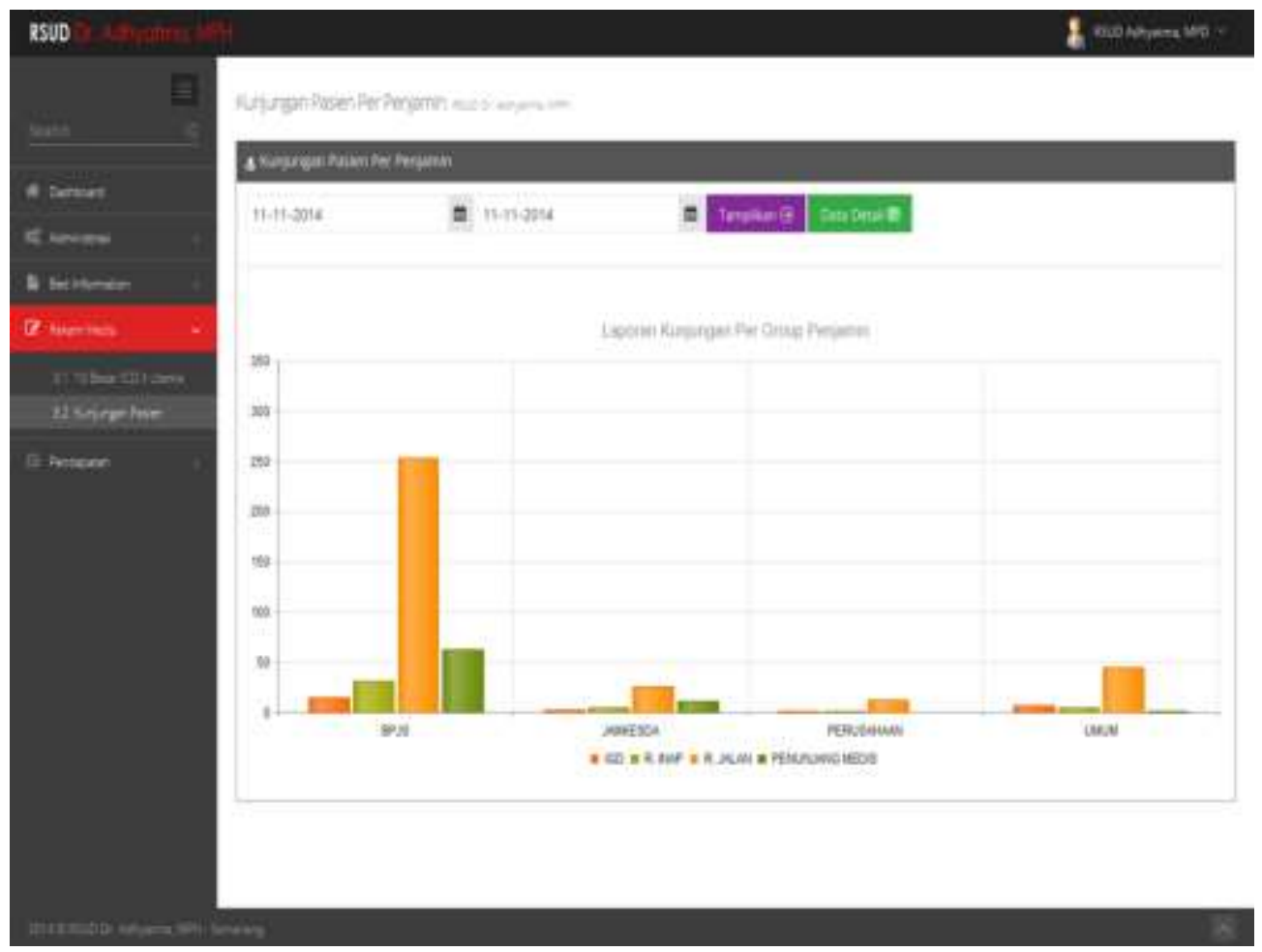

g. Gambar 7. Kunjungan Pasien Per Penjamin

\section{KESIMPULAN}

h. SIE Mobile akses smartphone

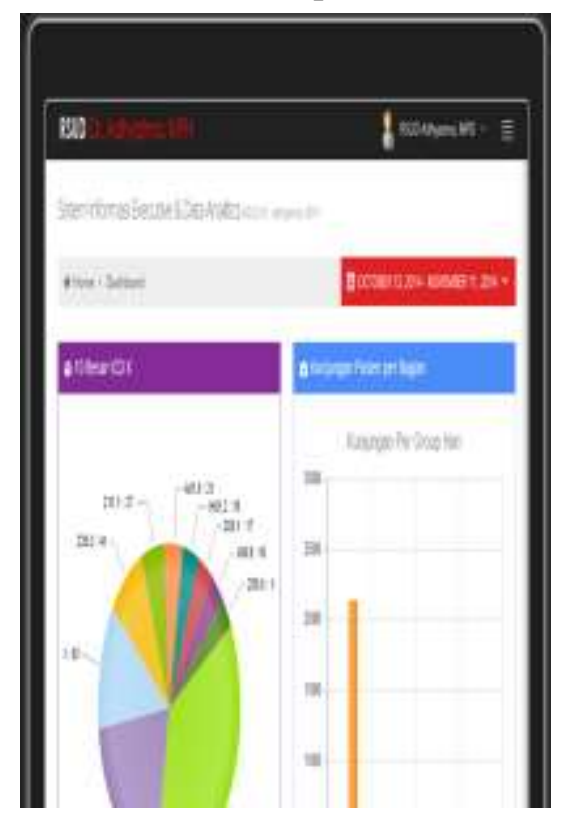

Gambar 8. SIE Mobile Akses Smartphone
Pembuatan Rancangan Sistem Informasi Eksekutif Pada RSUD Tugurejo berbasi web dan mobile bertujuan untuk mempermudah dan mempercepat para eksekutif dalam mengidentifikasi masalah dan pengambilan keputusan karena informasi yang didapat lebih akurat serta dapat diakses dimanapun berada.

Dari hasil penelitian yang sudah dilakukan saat ini,penulis mengharapkan pada penelitian berikutnya agar sistem registrasi pasien dapat dikembangkan dengan menggunakan web/mobile, sehingga dapat memudahkan proses pendaftaran pasien untuk mengurangi antrian yang selama ini sering terjadi.

\section{REFERENSI}

Amir M.S., Ekspor Impor Teori Dan Penerapanya,Seri Umum No.3,V Pt. Pustaka Binaman Pressindo,Jakarta, 1989, Hal. 61-83.

Bintang muthia (2005 : 13) diagram sebab akibat, qultum media Jakarta.

Davis, Gordon B. dan Margarethe H. Olson, 1985, Kerangka Dasar Sistem Informasi, Edisi 
Kedua, Pustaka Binaman Pressindo, Jakarta.

Husein umar,(2002) studi kelayakan bisnis Jakarta gramedia pustaka utama.

Jogiyanto HM, 2003, Sistem Teknologi Informasi, Andi, Yogyakarta Kadir, Abdul, 2003, Pengenalan Sistem Informasi, Andi, Yogyakarta.

Kurniawan, Bagus, 2002, Sistem Informasi Manajemen Dengan Visual Basic 6, Andi, Yogyakarta.

McLeod, Raymond, Jr, 1995, Management Informationn System, Seventh Edition, Prentice Hall, New Jersey.

McLeod, Raymond, Jr, 1996, Sistem Informasi Manajemen, Edisi Kedua, Prehalindo, Jakarta.

McLeod, Raymond, Jr, 2001, Sistem Informasi Manajemen Jilid 2 edisi ketujuh, PT. Prehalindo, Jakarta.

Mudjahidin. 2011. Jurnal Sistem Informasi.Pembuatan Sistem Informasi Manajemen Keluhan Pelanggan Berbasis Web dan SMS.Vol. 4(1), pp. 37-43.

Safaat H, Nazruddin. (2011). Pemrograman Aplikasi Mobile Smartphone dan Tablet Berbasis Android. Bandung: Informatika.

Apriansyah, Putra (2005) SISTEM INFORMASI EKSEKUTIF BERBASIS WEB Studi Kasus : Swalayan Koperasi Petra Pertamina Unit II Plaju. Jurnal Ilmiah Matrik, 07 (03). pp. 247260. ISSN 1411-1624 Retrieve from https://repository.unsri.ac.id/18559/

A Dawan, KI Satoto, AB Prasetijo (2010). Sistem Informasi Eksekutif Berbasis Web pada Fakultas Teknik Universitas Diponegoro (UNDIP). Retrieve from http://elearning.upnjatim.ac.id/courses/JSI311 9/work/5351aba5435a8ML2F099573.pdf

Edo Ostarisa, Januar Wibowo, Vicky M Taufik (2012). Sistem Informasi Eksekutif Berbasis Web Pada Stasiun Pengisian Bahan Bakar
Umum (SPBU) PT. Pertamina. Jurnal JSIKA Vol 1, No 2 (2012) Retrieve from https://jurnal.dinamika.ac.id/index.php/jsika/ar ticle/view/52. 